\title{
Sobre o artigo "Politicas públicas referentes às incapacidades físicas em hanseníase na virada do século: uma década de (des)controle?”
}

\author{
I ${ }^{1}$ Henrique Guimarães Aires e Silva, ${ }^{2}$ Rodrigo dos Santos Fagundes, ${ }^{3}$ Aline Baggio, \\ ${ }^{4}$ Chaiana Esmeraldino Mendes Marcon I
}

\begin{abstract}
1 Universidade do Sul de Santa Catarina. Tubarão-SC, Brasil (henriqueimbituba@hotmail.com). ORCID: 0000-0002-5742-3210
2 Universidade do Sul de Santa Catarina. Tubarão-SC, Brasil (fagundes.digao98@gmail.com). ORCID: 0000-0003-0507-2903

${ }^{3}$ Universidade do Sul de Santa Catarina. Tubarão-SC, Brasil (alinebaggio25@hotmail.com). ORCID: 0000-0001-5903-0026

${ }^{4}$ Universidade do Sul de Santa Catarina. Tubarão-SC, Brasil (chaianamarcon@gmail.com). ORCID: 0000-0001-7030-437X

Recebido em: 18/11/2019

Aprovado em: 16/12/2019

Revisado em: 21/02/2020
\end{abstract}

DOI: http://dx.doi.org/10.1590/\$0103-73312020300102

Expomos a seguir nossas consideraçóes sobre o artigo "Políticas públicas referentes às incapacidades físicas em hanseníase na virada do século: uma década de (des)controle?". O estudo de Mantellini et al., realizado no ano de 2019, traz à tona a história pós-descoberta da poliquimioterapia para tratamento da hanseníase que tanto negligencia as consequências da doença no contexto da cura clínica.

$\mathrm{O}$ acometimento do sistema nervosos periférico, perda de sensibilidade térmica, tátil e dolorosa, atrofias, paresias, paralisias e perda de membros, além de deformações faciais e da pele são marcas inesquecíveis da doença que podem permanecer mesmo após o tratamento. Em 1940, com introdução das sulfonas, o tratamento e a profilaxia da hanseníase puderam ser modificados. A necessidade de isolamento e segregação do doente, teoricamente, não era mais indicada, assim como sua internação em hospitais-colônias, sendo que o tratamento ambulatorial seria a escolha futura (EIDT, 2004).

Embora diante da cura da doença, essas características da hanseníase que serviam de "identidade" para os olhares alheios fizeram-na ser alvo de temor e preconceito ao longo da nossa história, inclusive nos dias de hoje, mesmo com o tratamento estabelecido. Posterior a isto, as políticas públicas foram destinadas à cura dos doentes, com quebra da cadeia de transmissão. 
Em 1941, na Era Vargas, foi feita a primeira Conferência Nacional de Saúde que normatizava o primeiro tratamento para hanseníase, sistematizando os papéis do governo, estados e municípios. Em 2005, a prevalência brasileira de pacientes com hanseníase era de 1,7 por 10 mil habitantes, sendo a segunda maior do mundo (SAVASSI, 2010). Já em 2018, a prevalência brasileira era de 1,47 por 10 mil habitantes (BRASIL, 2018), havendo diminuição do número de doentes - resultado dos esforços ao longo dos anos dos gestores de saúde. Mesmo imprescindíveis para a caminhada da erradicação da hanseníase, as políticas para tratar os doentes negligenciaram os curados, cercados de deformidades, preconceitos sociais e familiares, incapacitados e sob necessidade de cuidadores.

Os relatos de caso dos pacientes com hanseníase nos fazem perceber uma parcela do que é sentido pelos doentes diariamente. Os pacientes entrevistados no Vale do Jequitinhonha-MG sobre o estigma de ter hanseníase encobriam o fato de ter a doença, evitavam consultas ao médico para impedir sua identificação, assim como andavam com as lesôes cobertas, excluindo a possibilidade de serem julgados ações refletidas pelo histórico que a sociedade tem em marginalizar os doentes. Em geral, os pacientes entrevistados nesse estudo não sentem raiva por estares doentes e entendem o processo, mas a falta de compreensão geral que os relembra, diariamente, que já tiveram hanseníase (NEIVA; GRISOTTI, 2019).

Percebe-se que há um grande sofrimento ao redor dos doentes e que a crueldade vem sendo praticada há muitos anos. Além da doença, a falta de amparo após o tratamento também é um ponto crítico a ser investido na recuperação dos doentes. Carecemos de uma consciência coletiva e de medidas personalizadas que reinsiram os pacientes curados na sociedade, apesar dos raros centros de tratamento especializados e humanos. Lembramos facilmente dos protocolos de tratamento, mas esquecemos das pessoas "curadas" que não têm mais onde morar, que têm vergonha de sair de casa por lesóes corporais e/ou as incapacitadas de qualquer forma. Deveriam ser investidos em nível nacional projetos visando aproximar a população com a doença, reformando a concepção de uma doença incurável.

No sentido de quebrar o preconceito instituído ao longo dos anos com as deformaçóes características, poderia ser levantado o tema nas escolas por meio do Programa Saúde na Escola (PSE) do Governo Federal, principalmente nas regiōes com maior densidade de doentes. Além disso, a instituição de grupos de apoio para pacientes com Incapacidade Física em Hanseníase (IFH) é importante para que 
eles possam ter apoio psicológico e compartilhar suas vivências e evolução com a realidade de outros doentes. Assim, a reinserção no mercado de trabalho e no âmbito social deverá também acontecer o mais breve possível, possivelmente preservando a acessibilidade e garantindo a universalidade da dignidade humana.

Por fim, considerando que o Brasil é o segundo país com mais casos novos registrados no mundo de hanseníase (BRASIL, 2018), apreciamos o artigo original e gostaríamos de propor que haja mais atenção ao tema na área da Saúde Coletiva, no quesito de reintegração dos afetados por hanseníase e, idealmente, nas demais doenças que possam provocar debilidades físicas e emocionais cronicamente.

\section{Referências}

BRASIL. Ministério da Saúde. Departamento de Vigilância e Doenças Transmissíveis. Hanseniase Boletim epidemiologico, v.49, n.4, jan 2018. Disponível em: <http://www.saude.gov. br>. Acesso em: 10 nov. 2019.

EIDT, L. M. Breve história da hanseníase: sua expansão do mundo para as Américas, o Brasil e o Rio Grande do Sul e sua trajetória na saúde pública brasileira. Saude soc., São Paulo, v. 13, n. 2, p. 76-88, ago. 2004 Disponível em: <http://www.scielo.br/scielo.php?script=sci_ arttext\&pid=S0104-12902004000200008\&lng=en\&nrm=iso>. Acesso em: 10 out. 2019.

MANTELLINI, G. G.; GONCALVES, A.; PADOVANI, C. R. Políticas públicas referentes às incapacidades físicas em hanseníase na virada do século: uma década de (des)controle? Physis, Rio de Janeiro, v. 29, n. 1, e290105, 2019. Disponível em: <http://www.scielo.br/scielo. php?script=sci_arttext\&pid=S0103-73312019000100603\&lng=en\&nrm=iso >. Acesso em: 11 nov. 2019.

MARTINS, P. V.; CAPONI, S. Hanseníase, exclusão e preconceito: histórias de vida de mulheres em Santa Catarina. Ciênc. saúde coletiva, Rio de Janeiro, v. 15, supl. 1, p. 1047-1054, jun. 2010. Disponível em: <http://www.scielo.br/scielo.php?script=sci_arttext\&pid=S141381232010000700011\&lng=en\&nrm=iso>. Acesso em: 10 nov. 2019.

NEIVA, R. J.; GRISOTTI, M. Representaçóes do estigma da hanseníase nas mulheres do Vale do Jequitinhonha-MG. Physis, Rio de Janeiro, v. 29, n. 1, e290109, 2019. Disponível em: $<$ http://www.scielo.br/scielo.php?script=sci_arttext\&pid=S0103-73312019000100608\&lng=en \&nrm=iso>. Acesso em: 10 nov. 2019.

SAVASSI, L. C. M. Hanseníase: políticas públicas e qualidade de vida de pacientes e seus cuidadores. 2010. 196 f. Dissertação (Mestrado) - Curso de Ciências da Saúde, Fundação Oswaldo Cruz, Centro de Pesquisas René Rachou, Belo Horizonte, 2010. 